\title{
Determinants of excessive daytime sleepiness in two First Nation communities
}

\author{
Ina van der Spuy ${ }^{1}$, Chandima P. Karunanayake², James A. Dosmann ${ }^{2,3}$, Kathleen McMullin ${ }^{4}$, Gaungming Zhao ${ }^{2}$, \\ Sylvia Abonyi ${ }^{5}$, Donna C. Rennie ${ }^{2,6}$, Joshua Lawsonn ${ }^{2,3}$, Shelley Kirychuk ${ }^{2,3}$, Judith MacDonald ${ }^{7}$, Laurie Jimmy ${ }^{8}$, \\ Niels Koehncke ${ }^{2,3}$, Vivian R. Ramsden ${ }^{9}$, Mark Fenton ${ }^{10}$, Gregory P. Marchildon ${ }^{11}$, Malcolm King ${ }^{12}$ \\ and Punam Pahwa ${ }^{2,5^{*}}$
}

\begin{abstract}
Background: Excessive daytime sleepiness may be determined by a number of factors including personal characteristics, co-morbidities and socio-economic conditions. In this study we identified factors associated with excessive daytime sleepiness in 2 First Nation communities in rural Saskatchewan.

Methods: Data for this study were from a 2012-13 baseline assessment of the First Nations Lung Health Project, in collaboration between two Cree First Nation reserve communities in Saskatchewan and researchers at the University of Saskatchewan. Community research assistants conducted the assessments in two stages. In the first stage, brochures describing the purpose and nature of the project were distributed on a house by house basis. In the second stage, all individuals age 17 years and older not attending school in the participating communities were invited to the local health care center to participate in interviewer-administered questionnaires and clinical assessments. Excessive daytime sleepiness was defined as Epworth Sleepiness Scale score $>10$.

Results: Of 874 persons studied, 829 had valid Epworth Sleepiness Scale scores. Of these, 91(11.0\%) had excessive daytime sleepiness; $12.4 \%$ in women and $9.6 \%$ in men. Multivariate logistic regression analysis indicated that respiratory comorbidities, environmental exposures and loud snoring were significantly associated with excessive daytime sleepiness.
\end{abstract}

Conclusions: Excessive daytime sleepiness in First Nations peoples living on reserves in rural Saskatchewan is associated with factors related to respiratory co-morbidities, conditions of poverty, and loud snoring.

Keywords: First Nations, Indigenous, Sleepiness, Epworth sleepiness scale, Co-morbidities, Poverty, Snoring

\section{Background}

Excessive daytime sleepiness (EDS) is a common problem in various populations [1-5]. It has been associated with age $[3,5]$, sex [5-7], body mass index (BMI) [8-10], shift work [11], snoring [12-14], comorbidities [15], social conditions $[5,16]$ and obstructive sleep apnea $[2,17,18]$. Deleterious outcomes of EDS include poor work performance [19], motor vehicles accidents [20, 21], and work injuries $[22,23]$. We have recently observed EDS prevalence

\footnotetext{
* Correspondence: pup165@mail.usask.ca

${ }^{2}$ Canadian Centre for Health and Safety in Agriculture, University of

Saskatchewan, 104 Clinic Place, Saskatoon, SK S7N 2Z4, Canada

${ }^{5}$ Department of Community Health and Epidemiology, College of Medicine,

University of Saskatchewan, 107 Wiggins Road, Saskatoon, SK S7N 5E5,

Canada

Full list of author information is available at the end of the article
}

of $15.9 \%$ to $20.8 \%$ in Caucasian populations in rural Saskatchewan [5, 24]. High rates of EDS have been documented in New Zealand Maori Indigenous populations (21.3\%) compared to New Zealand non-Maori populations (13.9\%) [25]. Knowledge is limited for First Nations populations.

First Nations people in Canada characteristically have high rates of respiratory morbidities, including asthma and chronic obstructive pulmonary disease (COPD) [26-30]. Among First Nations people living on reserves in Canada, 59\% engaged in non-traditional use of tobacco (smoking) [31]. Age standardized hospital separation rates in Western Canada for Indigenous people for all respiratory diseases in 2000 were high at 3040/100,000 compared to $920 / 100,000$ in the general population [27]. 
First Nations populations in Canada are characterized by disadvantaged socio-economic status [32]. The average annual income in 2010 was $\$ 18,586$ for on-reserve First Nations people compared to $\$ 41,052$ for other Canadians [32]. Twenty-eight percent of on-reserve First Nations persons live in crowded housing conditions of more than one person per room, compared to $4 \%$ of non-Indigenous persons in Canada [33]. Forty-three percent of persons living on-reserves had homes in need of major repairs [33]. Poor housing conditions are associated with dampness and mold which may be associated with deleterious respiratory outcomes [27].

In Canada, the term commonly used to refer to people registered under the Indian Act is "First Nations" [34]. There is limited information on EDS among First Nations people in Canada [35]. In 2011, of the 1,033,381 persons in Saskatchewan, 103,205 were First Nations [36]. The objective of this study was to identify the prevalence of EDS and to investigate factors contributing to EDS among adult First Nations people living in two reserve communities in rural Saskatchewan.

\section{Methods}

\section{Study sample}

The data for this study are from a 2012-13 baseline assessment of the First Nations Lung Health Project which was conducted as part of a research collaboration between two Cree First Nation communities in Saskatchewan and researchers at the University of Saskatchewan [37]. The sampling frame was all currently residing community members based on 321 households with 810 adults in Community A, and 259 households with 760 adults in Community B [37]. Baseline data from 432 adults living in 173 households (53.9\% household participation rate) in Community A and 442 adults living in 233 households (89.9\% household participation rate) in Community B were obtained. Of 874 persons studied, 829 had valid Epworth Sleepiness Scale scores obtained from participants aged 17 years and older.

\section{Data acquisition}

The study coordinator (KM) is from the LaRonge Cree First Nation. The clinical aspects of the study were conducted primarily by students from the communities who were attending post-secondary institutions and who were available during the summer holiday period. The students were attending nursing, education and social work training courses during the school year, and were trained in the techniques involved at the base laboratory of the Canadian Centre for Health in Agriculture prior to the commencement of the study. They were supervised by the project coordinator and other research staff. The baseline assessment was conducted in two stages. The rationale and purpose of the study were determined with representatives of the communities including Elders, community leadership, health provider personnel and students. The first stage consisted of introducing the project to the community by meetings and brochures. In the second stage, all individuals age 17 years and older not attending school were invited to the community health care center for interviewer-administered questionnaires and participation in clinical assessments. The degree of sleepiness in individuals was based on their response to Epworth Sleepiness Scale (ESS) questionnaire [38-41]. ESS shows good reliability and validity $[39,41]$. We used an ESS score of 11 to 24 as indicating high ESS score [40] which we considered the principal outcome. Independent variables of interest were self-reported age, sex, height, weight, $\left(\mathrm{BMI}, \mathrm{kg} / \mathrm{m}^{2}\right.$ ) (overweight $\mathrm{BMI}=25-29.9$; obese $\mathrm{BMI} \geq 30$ ), education level (completed post-secondary, completed university, completed high school, less than high school) marital status, non-traditional use of tobacco (smoking) (current, former, never) and alcohol use. "Doctor ever diagnosed" conditions included sinus trouble, heart problem, tuberculosis, attack of bronchitis, emphysema, chronic bronchitis, COPD and asthma. Other factors elicited by the questionnaire included chronic cough/ chronic phlegm and shortness of breath (SOB), loud snoring, money at end of month, annual household income level, state of house repairs, and number of persons per room as an index of crowding. For the analysis, we used the term "chronic lung disease" to include one or more of emphysema, chronic bronchitis, chronic cough/chronic phlegm and COPD.

\section{Statistical analysis}

Statistical analysis was conducted using SAS version 9.4 (SAS Institute Inc., Cary, NC, USA).

Logistic regression models were used to assess relationships between ESS and covariates. A multilevel logistic regression model by generalized estimating equations approach was used to fit the model with individuals (first level) clustering within households (second level). The significant contribution of potential risk factors, confounders and interactive effects was determined by fitting a series of multilevel models. Variables with $p<0.20$ in univariate analysis became candidates for the multivariable model. The variables retained in the final multivariable model included those that were statistically significant (i.e. $p<0.05$ ) as well as sex, non-traditional use of tobacco, and BMI. Odds ratios (ORs) and 95\% confidence intervals (CIs) were used to present the strength of associations.

\section{Results}

The mean $( \pm S D)$ age of the 408 men who participated was $33.7( \pm 13.9)$ years and of the 421 women was 35.9 $( \pm 14.4)$ years. Fifty percent had completed high school (Grade 12). Twenty-nine percent were overweight and 
$35 \%$ were obese. Non-traditional use of tobacco (current smoking) was present in $78.3 \%$, ex-smoking in $12.2 \%$, and never smoking in $9.5 \%$ persons. Loud snoring was reported by $17.0 \%$ men and $14.8 \%$ women. There were $91(11.0 \%)$ adults with an ESS score $>10$. More women (12.4\%) than men (9.6\%) had ESS scores $>10$.

As shown in Table 1, unadjusted univariate analysis showed that older age [ $>55$ years of age, OR 4.46 (95\% CI 2.34 to 8.52 )] was significantly associated with high ESS score. With regard to doctor diagnosed conditions significantly associated with the risk of having high ESS scores included: sinus trouble [OR 2.24 (95\% CI 1.42 to 3.54)], heart problems [OR 2.55 (95\% CI 1.47 to 4.41 )], tuberculosis [OR 2.71 (95\% CI 1.30 to 5.63)], attack of bronchitis [OR 2.22 (95\% CI 1.38 to 3.56)], chronic lung disease [OR 2.35 (95\% CI 1.51 to 3.64)], and SOB [OR 3.15 (95\% CI 1.92 to 5.18)]. Loud snoring [OR 1.68 (95\% CI 1.02 to 2.77)] was also associated with high ESS scores. House in need of repairs and crowding (more than one person per room) were significant at $p<0.2$ and hence included in the multivariate model as potential confounders.

Multivariable logistic regression analysis (Table 2) indicated a trend towards statistical significance for age greater than 55 years [OR 2.27 (95\% CI 0.94 to 5.52 ); $p$ $=0.07$ ]. Doctor ever diagnosed tuberculosis [OR 3.02 (95\% CI 1.32 to 6.87)] was significantly related to high ESS. Chronic lung disease [OR 2.01 (95\% CI 1.15 to 3.50)] and SOB [OR 2.76 (95\% CI 1.52 to 4.99)] were significantly related to high ESS scores. Loud snoring [OR 2.21 (95\% CI 1.13 to 4.33)] continued to be an associated condition. Socio-economic factors of low income [OR 2.59 (95\% CI 1.20 to 5.60)], house in need of repairs [OR 2.40 (95\% CI 1.18 to 4.87 )] and more than one person per room [OR 2.07 (95\% CI 1.16 to 3.69)] were significantly associated with high ESS scores. There were no associations for BMI and smoking with high ESS scores.

\section{Discussion}

The findings from this study highlight the strong associations of certain respiratory co-morbidities, indicators of poverty and snoring with EDS among people living on two on-reserve First Nation communities in the Province of Saskatchewan in Canada.

In addition, annual household income (less than $\$ 10,000$ per year), houses in need of repairs, and overcrowding, all indicators of social determinants of health consistent with poverty [42-44] were associated with high ESS scores. The relationship of poverty to sleep disturbance has been described for non-Indigenous populations [45-47]. Social determinants of health of which low socioeconomic status is one, are associated with co-morbidities [48-50]. Respiratory co-morbidities associated with EDS in the present study were doctor ever diagnosed tuberculosis, reported chronic lung disease, and SOB. The significant relationship between SOB and EDS in our study is consistent with the observations of Kaneita et al. [51] The association between EDS and chronic lung disease in our study is consistent with the findings of Karachaliou et al. [52] and Koutsourelakis et al. [53] We did not find reports linking past tuberculosis with high ESS score. However, chronic lung disease has been observed in former tuberculosis patients [54], and it is possible that the apparent relationship between past tuberculosis and high ESS score in our study is as a result of chronic lung disease in former tuberculosis patients.

In the univariate analysis, older age ( $\geq 55$ years of age) was associated with high ESS score. In the multivariate analysis borderline significance for age persisted. Increasing age is recognized as being associated with increased risk for EDS $[3,5]$. The prevalence of high ESS scores in this fairly young population (men 33.7 years, women 35.9 years) that we studied was $11.0 \%$. The prevalence of high ESS score (25.9\%) in the oldest (>55 year) age group was higher than in the nonIndigenous population (18.5\%) of rural Saskatchewan described by Gjevre et al. [5], and more like that described by Paine et al. for the Maori population (21.3\%) in New Zealand [25].

Obesity has been identified as an independent predictor of EDS in both men and women.' $[55,56]$ However, in our study the effect of overweight and obesity on high ESS scores was not statistically significant, likely due to lack of variability with $64 \%$ of the population being either overweight or obese. Following discussion with the communities, the high percentage of obesity can be addressed in future by the introduction of healthier eating and exercise programs.

The significance of EDS for the health of the populations participated is important to consider. EDS is a hallmark feature of obstructive sleep apnea [2, 17, 18]. Among those with high ESS scores in the populations that we studied, there may be a high prevalence of undiagnosed and untreated sleep disordered breathing with all of the implications for cardiovascular outcomes [57, 58] and accidents $[22,59,60]$.

Mechanisms by which these factors might affect EDS merit discussion. We have shown that socio-economic factors relate to respiratory status in rural people [61]. Respiratory co-morbidities may enhance EDS [62] and/or upper airway instability leading to sleep disordered breathing [63] and concomitant EDS [64]. It has been demonstrated that environmental exposures are associated with increased sleep disordered breathing, possibly because of enhanced upper airway inflammation [65]. Our results show that homes requiring repairs are associated with high ESS scores. It is possible that endotoxin or mold 
Table 1 Univariate associations between ESS score $>10$ and independent variables of interest ${ }^{a}$

\begin{tabular}{|c|c|c|c|}
\hline \multirow[t]{2}{*}{ Variables } & \multicolumn{2}{|l|}{ ESS Score, $n(\%)$} & \multirow{2}{*}{$\begin{array}{l}\text { Univariate OR } \\
(95 \% \mathrm{Cl})\end{array}$} \\
\hline & Normal $(n=738)$ & Abnormal $(n=91)$ & \\
\hline \multicolumn{4}{|l|}{ Demographics } \\
\hline \multicolumn{4}{|l|}{ Sex } \\
\hline Female (reference) & $369(87.6)$ & $52(12.4)$ & 1.00 \\
\hline Male & $369(90.4)$ & $39(9.6)$ & $0.76(0.48-1.20)$ \\
\hline \multicolumn{4}{|l|}{ Age, in years } \\
\hline 17-25 (reference) & $266(92.7)$ & $21(7.3)$ & 1.00 \\
\hline $26-35$ & $180(88.2)$ & $24(11.8)$ & $1.71(0.90-3.26)$ \\
\hline $36-45$ & $119(89.5)$ & $14(10.5)$ & $1.45(0.69-3.03)$ \\
\hline $46-55$ & $113(91.1)$ & $11(8.9)$ & $1.30(0.58-2.90)$ \\
\hline$>55$ & $60(74.1)$ & $21(25.9)$ & $4.46(2.34-8.52)$ \\
\hline \multicolumn{4}{|l|}{ Educational level } \\
\hline Completed postsecondary education (reference) & $103(88.8)$ & $13(11.2)$ & 1.00 \\
\hline Completed university & $89(88.1)$ & $12(11.9)$ & $1.02(0.41-2.53)$ \\
\hline Completed high school & $191(92.7)$ & $15(7.3)$ & $0.61(0.26-1.43)$ \\
\hline Less than high school & $354(87.6)$ & $50(12.4)$ & $1.12(0.56-2.25)$ \\
\hline \multicolumn{4}{|l|}{ Marital status } \\
\hline Widowed/divorced/separated/single (reference) & $430(88.5)$ & $56(11.5)$ & 1.00 \\
\hline Married/common in law & $288(89.4)$ & $34(10.6)$ & $0.88(0.56-1.38)$ \\
\hline \multicolumn{4}{|l|}{ Body mass index, $\mathrm{kg} / \mathrm{m}^{2}$} \\
\hline Normal (<25) (reference) & $251(90.0)$ & $28(10.0)$ & 1.00 \\
\hline Overweight (25-29.9) & $213(88.4)$ & $28(11.6)$ & $1.14(0.64-2.05)$ \\
\hline Obese $(\geq 30)$ & $258(88.4)$ & $34(11.6)$ & $1.15(0.68-1.95)$ \\
\hline \multicolumn{4}{|l|}{ Smoke status } \\
\hline Non-smoker (reference) & $68(86.1)$ & $11(13.9)$ & 1.00 \\
\hline Ex-smoker & $85(84.2)$ & $16(15.8)$ & $1.27(0.51-3.16)$ \\
\hline Current smoker & $585(90.1)$ & $64(9.9)$ & $0.72(0.36-1.42)$ \\
\hline \multicolumn{4}{|l|}{ In past 12 months, had $\geq 5$ drinks on one occasion } \\
\hline No (reference) & $156(88.1)$ & $21(11.9)$ & 1.00 \\
\hline Yes & $579(89.6)$ & $67(10.4)$ & $0.84(0.50-1.41)$ \\
\hline \multicolumn{4}{|l|}{ Employment status } \\
\hline Yes (reference) & $388(89.2)$ & $47(10.8)$ & 1.00 \\
\hline No & $346(88.7)$ & $44(11.3)$ & $1.05(0.67-1.64)$ \\
\hline \multicolumn{4}{|l|}{ Doctor ever diagnosed: } \\
\hline \multicolumn{4}{|l|}{ Sinus trouble } \\
\hline No (reference) & $470(91.8)$ & $42(8.2)$ & 1.00 \\
\hline Yes & $189(83.3)$ & $38(16.7)$ & $2.24(1.42-3.54)$ \\
\hline \multicolumn{4}{|l|}{ Heart problem } \\
\hline No (reference) & $674(90.2)$ & $73(9.8)$ & 1.00 \\
\hline Yes & $62(78.5)$ & $17(21.5)$ & $2.55(1.47-4.41)$ \\
\hline \multicolumn{4}{|l|}{ Tuberculosis } \\
\hline No (reference) & $597(90.5)$ & $63(9.5)$ & 1.00 \\
\hline Yes & $43(78.2)$ & $12(21.8)$ & $2.71(1.30-5.63)$ \\
\hline
\end{tabular}


Table 1 Univariate associations between ESS score $>10$ and independent variables of interest ${ }^{\mathrm{a}}$ (Continued)

\begin{tabular}{|c|c|c|c|}
\hline \multirow[t]{2}{*}{ Variables } & \multicolumn{2}{|l|}{ ESS Score, $n(\%)$} & \multirow{2}{*}{$\begin{array}{l}\text { Univariate OR } \\
(95 \% \mathrm{Cl})\end{array}$} \\
\hline & Normal $(n=738)$ & Abnormal $(n=91)$ & \\
\hline \multicolumn{4}{|l|}{ Attack of bronchitis } \\
\hline No (reference) & $466(91.6)$ & $43(8.4)$ & 1.00 \\
\hline Yes & $180(82.9)$ & $37(17.1)$ & $2.22(1.38-3.56)$ \\
\hline \multicolumn{4}{|l|}{ Ever had asthma } \\
\hline No (reference) & $616(89.3)$ & $74(10.7)$ & 1.00 \\
\hline Yes & $122(87.8)$ & $17(12.2)$ & $1.12(0.64-1.95)$ \\
\hline \multicolumn{4}{|l|}{ Questionnaire ascertained conditions } \\
\hline \multicolumn{4}{|l|}{ Chronic Lung Disease ${ }^{\mathrm{b}}$} \\
\hline No (reference) & $554(91.6)$ & $51(8.4)$ & 1.00 \\
\hline Yes & $184(82.1)$ & $40(17.9)$ & $2.35(1.51-3.64)$ \\
\hline \multicolumn{4}{|l|}{$\mathrm{SOB}$} \\
\hline No (reference) & $367(94.3)$ & $22(5.7)$ & 1.00 \\
\hline Yes & $365(84.1)$ & $69(15.9)$ & $3.15(1.92-5.18)$ \\
\hline \multicolumn{4}{|l|}{ Loud snoring } \\
\hline No (reference) & $626(89.9)$ & $70(10.1)$ & 1.00 \\
\hline Yes & $110(84.0)$ & $21(16.0)$ & $1.68(1.02-2.77)$ \\
\hline \multicolumn{4}{|l|}{ Socio-economic Status } \\
\hline \multicolumn{4}{|l|}{ Money left over at end of the month } \\
\hline Some (reference) & $188(86.2)$ & $30(13.8)$ & 1.00 \\
\hline Just enough & $171(90.5)$ & $18(9.5)$ & $0.64(0.34-1.22)$ \\
\hline Not enough & $340(90.2)$ & $37(9.8)$ & $0.65(0.37-1.15)$ \\
\hline \multicolumn{4}{|l|}{ Annual household income } \\
\hline$\$ 20,000$ and over (reference) & $199(91.7)$ & $18(8.3)$ & 1.00 \\
\hline$\$ 10,000-\$ 19,999$ & $106(86.9)$ & $16(13.1)$ & $1.58(0.76-3.27)$ \\
\hline Less than $\$ 10,000$ & $188(85.8)$ & $31(14.2)$ & $1.75(0.88-3.47)$ \\
\hline Refusal/not stated & $245(90.4)$ & $26(9.6)$ & $1.09(0.54-2.19)$ \\
\hline \multicolumn{4}{|l|}{ Home need repairing } \\
\hline No (reference) & $205(89.5)$ & $24(10.5)$ & 1.00 \\
\hline Minor & $188(85.1)$ & $33(14.9)$ & $1.51(0.82-2.80)$ \\
\hline Major & $188(85.1)$ & $28(8.7)$ & $0.81(0.46-1.43)$ \\
\hline \multicolumn{4}{|l|}{ Home crowded status (person per room) } \\
\hline one or less person per room (reference) & $188(85.1)$ & $52(9.7)$ & 1.00 \\
\hline More than one person per room & $215(86.3)$ & $34(13.7)$ & $1.44(0.88-2.36)$ \\
\hline
\end{tabular}

${ }^{a}$ Row percentages are presented

b"Chronic Lung Disease" includes groups of chronic cough, chronic phlegm, chronic bronchitis, emphysema and chronic obstructive pulmonary disease

exposure associated with dampness in these homes could result in upper airway inflammation $[66,67]$ thus acting by a similar mechanism. Cigarette smoking may enhance OSA [68] with consequent increased EDS. But like our finding for BMI, smoking was not a significant contributor to EDS, likely because smoking was highly prevalent in the population (78.3\% current smokers; $12.2 \%$ ex-smokers). The high prevalence of non-traditional use of tobacco (smoking) is being address by a community-chosen intervention called the "Green Light Program". The Green Light
Program is an evidence-informed, community-level intervention which identifies and celebrates homes that are smoke-free. Currently, in excess of $50 \%$ of the homes in both communities are smoke-free.

Certain strengths and limitations apply to our study. Strengths include the size of the populations studied, and the consistently strong of associations with respiratory co-morbidities, indices of social determinants of health, and snoring. This study adds to a small but growing body of knowledge on sleep issues affecting 
Table 2 Multivariable logistic regression of the association between ESS score > 10 and independent variables of interest

\begin{tabular}{|c|c|c|}
\hline Variables & Multivariate OR (95\% Cl) & $P$-value \\
\hline \multicolumn{3}{|l|}{ Sex } \\
\hline Female (reference) & 1.00 & \\
\hline Male & $0.67(0.36-1.22)$ & 0.189 \\
\hline \multicolumn{3}{|l|}{ Age, in years } \\
\hline 17-25 (reference) & 1.00 & \\
\hline $26-35$ & $2.06(0.98-4.35)$ & 0.057 \\
\hline $36-45$ & $1.17(0.49-2.82)$ & 0.722 \\
\hline $46-55$ & $0.84(0.34-2.07)$ & 0.709 \\
\hline$>55$ & $2.27(0.94-5.52)$ & 0.070 \\
\hline \multicolumn{3}{|l|}{ Body mass index, kg/m2 } \\
\hline Normal (<25) (reference) & 1.00 & \\
\hline Overweight (25-29.9) & $0.75(0.38-1.49)$ & 0.409 \\
\hline Obese $(>=30)$ & $0.49(0.23-1.03)$ & 0.061 \\
\hline \multicolumn{3}{|l|}{ Smoke status } \\
\hline Non-smoker (reference) & 1.00 & \\
\hline Ex-smoker & $1.37(0.44-4.24)$ & 0.586 \\
\hline Current smoker & $0.52(0.21-1.29)$ & 0.159 \\
\hline \multicolumn{3}{|l|}{ Tuberculosis } \\
\hline No (reference) & 1.00 & \\
\hline Yes & $3.02(1.32-6.87)$ & 0.009 \\
\hline \multicolumn{3}{|l|}{ Chronic Lung Disease } \\
\hline No (reference) & 1.00 & \\
\hline Yes & $2.01(1.15-3.50)$ & 0.014 \\
\hline \multicolumn{3}{|l|}{ Shortness of breath } \\
\hline No (reference) & 1.00 & \\
\hline Yes & $2.76(1.52-4.99)$ & 0.001 \\
\hline \multicolumn{3}{|l|}{ Loud snoring } \\
\hline No (reference) & 1.00 & \\
\hline Yes & $2.21(1.13-4.33)$ & 0.021 \\
\hline \multicolumn{3}{|l|}{ Annual household income } \\
\hline More than $\$ 20,000$ (reference) & 1.00 & \\
\hline$\$ 10,000-\$ 19,999$ & $1.93(0.84-4.41)$ & 0.119 \\
\hline Less than $\$ 10,000$ & $2.59(1.20-5.60)$ & 0.016 \\
\hline Refusal/not stated & $1.37(0.61-3.08)$ & 0.450 \\
\hline \multicolumn{3}{|l|}{ Home need repairing } \\
\hline No (reference) & 1.00 & \\
\hline Minor & $2.40(1.18-4.87)$ & 0.015 \\
\hline Major & $0.90(0.47-1.75)$ & 0.766 \\
\hline \multicolumn{3}{|l|}{ Home crowded status (person per room) } \\
\hline one or less person per room (reference) & 1.00 & \\
\hline More than one person per room & $2.07(1.16-3.69)$ & 0.014 \\
\hline
\end{tabular}


Indigenous populations. A major limitation is the recall-bias of medical history due to the cross-sectional nature of the study. One of other limitations is information bias due to conducting the study in First Nation communities. That is, we hired local people to conduct the interviews and closeness among community members could lead to information bias. Response rates for household surveys and individual surveys in Community A were lower compared to Community B. Compared to Community B, Community A is spread over a much wider area of land resulting in lower response rates due to difficulties in access to the health clinic [37]. Other potential limitation of the study is the lack of validation of the ESS in First Nations people. While all the younger people in this study spoke English, on site interpretation was required for some of the older participants. It is possible that the ESS may be a culturally sensitive tool [69], with potential observer bias when used in non-Caucasian cultures.

\section{Conclusions}

This study demonstrates relationships between respiratory co-morbidities and environmental exposures, and EDS in two First Nation communities. It is imperative to validate the use of the ESS in and with First Nations people. An important priority is to work with the communities involved to elucidate the burden of sleep disorders among First Nations people living on reserves so that the tools can be shared and used in and with other First Nation communities in Canada.

\section{Abbreviations \\ BMI: Body Mass Index; COPD: Chronic Obstructive Pulmonary Disease; EDS: Excessive Daytime Sleepiness; ESS: Epworth Sleepiness Scale; SOB: Shortness of Breath}

\section{Acknowledgements}

We are grateful for the contributions of Elders, community leaders that facilitated the engagement necessary for the study, and all individuals who donated their time to participate. The First Nations Lung Health Project was funded by a grant from the Canadian Institutes of Health Research "Assess, Redress, Re-assess: Addressing Disparities in Respiratory Health among First Nations People", CIHR MOP-246983-ABH-CCAA-11829. The team consists of: James Dosman, MD (Designated Principal Investigator, University of Saskatchewan, Saskatoon, SK Canada); Punam Pahwa, PhD (Co-Principal Investigator, University of Saskatchewan, Saskatoon SK Canada); Late Jo-Ann Episkenew, PhD (Co-Principal Investigator), Former Director of Indigenous People's Health Research Centre, University of Regina, SK Canada), Sylvia Abonyi, PhD (Co-Principal Investigator, University of Saskatchewan, Saskatoon, SK Canada); Co-Investigators: Mark Fenton, MD, Bonnie Janzen, PhD, Chandima Karunanayake, PhD, Malcolm King, PhD, Shelly Kirychuk, PhD, Niels Koehncke, MD, Joshua Lawson, PhD, Greg Marchildon, PhD, Lesley McBain, PhD, Donna Rennie, PhD, Vivian R Ramsden, RN, PhD, Ambikaipakan Senthilselvan, PhD; Collaborators: Amy Zarzeczny, BA, LLM; Louise Hagel, MSc, Breanna Davis, MD, John Dosman, MD, Roland Dyck, MD, Thomas Smith-Windsor, MD, William Albritton, MD, PhD; External Advisor: Janet Smylie, MD, MPH; Project Manager: Kathleen McMullin, MEd; Community Partners: Jeremy Seeseequasis, BA; Laurie Jimmy, RN; Judith Macdonald, RN, BScN; Arnold Naytowhow.

\section{Funding}

The First Nations Lung Health Project was funded by a grant from the Canadian Institutes of Health Research - "Assess, Redress, Re-assess:
Addressing Disparities in Respiratory Health among First Nations People," Canadian Institutes of Health Research MOP-246983-ABH-CCAA-11829. Principal Investigator: James A Dosman; Co-Principal Investigators: Punam Pahwa, Sylvia Abonyi, Jo-Ann Episkenew.

Availability of data and materials

The datasets generated and/or analyzed during the current study are not publicly available.

\section{Authors contributions}

$J A D, S A, D C R, J L$, SK contributed substantially to the study design, acquisition of data and interpretation, and the writing of the manuscript. PP and CPK contributed substantially to the study design, acquisition of data, data analysis and interpretation, and the writing of the manuscript. $\mathrm{KM}, J \mathrm{M}, \mathrm{L} \mathrm{c}$ contributed to acquisition of data and manuscript preparation. IvdS and GZ contributed to data analysis, interpretation and manuscript preparation. VRR contributed to interpretation of data and manuscript preparation. NK, MF, GPM and MK contributed to study design, interpretation and manuscript preparation. All authors have read and approved the final manuscript.

\section{Ethics approval and consent to participate}

The study was approved by the Biomedical Research Ethics Board of the University of Saskatchewan (Certificate No. Bio \#12-89) and adhered to Chapter 9 criteria of the Canadian Tri-Council requirements for conducting research with Indigenous people. Written consent was obtained from all participants.

\section{Consent for publication}

Not applicable.

\section{Competing interests}

The authors declare that they have no competing interests.

\section{Publisher's Note}

Springer Nature remains neutral with regard to jurisdictional claims in published maps and institutional affiliations.

\section{Author details}

${ }^{1}$ School of Physical Therapy, University of Saskatchewan, 104 Clinic Place, Saskatoon, SK S7N 2Z4, Canada. ${ }^{2}$ Canadian Centre for Health and Safety in Agriculture, University of Saskatchewan, 104 Clinic Place, Saskatoon, SK S7N 2Z4, Canada. ${ }^{3}$ Department of Medicine, College of Medicine, University of Saskatchewan, 103 Hospital Drive, Saskatoon, SK S7N 0W8, Canada. ${ }^{4}$ First Nations University of Canada, Prince Albert Campus, 1301 Central Avenue, Prince Albert, SK S6V 4W1, Canada. ${ }^{5}$ Department of Community Health and Epidemiology, College of Medicine, University of Saskatchewan, 107 Wiggins Road, Saskatoon, SK S7N 5E5, Canada. ${ }^{6}$ College of Nursing, University of Saskatchewan, 104 Clinic Place, Saskatoon, SK S7N 2Z4, Canada. ${ }^{7}$ Community A, Duck Lake, Saskatoon, SK, Canada. ${ }^{8}$ Community B, Montreal Lake, Saskatoon, SK, Canada. ${ }^{9}$ Department of Academic Family Medicine, University of Saskatchewan, West Winds Primary Health Centre, 3311 Fairlight Drive, Saskatoon, SK S7M 3Y5, Canada. ${ }^{10}$ Division of Respirology, Critical Care and Sleep Medicine, Department of Medicine, College of Medicine, University of Saskatchewan, 103 Hospital Drive, Saskatoon, SK S7N OW8, Canada. ${ }^{11}$ Institute of Health Policy, Management and Evaluation, University of Toronto, Suite 425, 155 College Street, Toronto, ON M5T 3M6, Canada. ${ }^{12}$ Faculty of Health Sciences, Simon Fraser University, 8888 University Drive, Burnaby, BC V5A 156, Canada.

Received: 10 July 2017 Accepted: 29 November 2017

Published online: 12 December 2017

\section{References}

1. Ford ES, Cunningham TJ, Giles WH, Croft JB. Trends in insomnia and excessive daytime sleepiness among U.S. adults from 2002 to 2012. Sleep Med. 2015;16(3):372-8.

2. Young T, Peppard PE, Gottlieb DJ. Epidemiology of obstructive sleep apnea. A population health perspective. Am J Respir Crit Care Med. 2002;165(9): 1217-39. 
3. Joo S, Baik I, Yi H, Jung K, Kim J, Shin C. Prevalence of excessive daytime sleepiness and associated factors in the adult population of Korea. Sleep Med. 2009;10(2):182-8.

4. Nugent AM, Gleadhill I, McCrum E, Patterson CC, Evans A, MacMahon J. Sleep complaints and risk factors for excessive daytime sleepiness in adult males in Northern Ireland. J Sleep Res. 2001;10(1):69-74.

5. Gjevre JA, Pahwa P, Karunanayake C, et al. Excessive daytime sleepiness among rural residents in Saskatchewan. Can Respir J. 2014;21(4):227-33.

6. Vashum KP, McEvoy MA, Hancock SJ, et al. Prevalence of and associations with excessive daytime sleepiness in an Australian older population. Asia Pac J Public Health. 2015:27(2):NP2275-84.

7. Larsson LG, Lindberg A, Franklin KA, Lundbäck B. Gender differences in symptoms related to sleep apnea in a general population and in relation to referral to sleep clinic. Chest. 2003;124(1):204-11.

8. Dagan Y, Doljansky JT, Green A, Weiner A. Body mass index (BMI) as a firstline screening criterion for detection of excessive daytime sleepiness among professional drivers. Traffic Inj Prev. 2006;7(1):44-8.

9. Mokhber S, Ravanbakhsh PZ, Jesmi F, Pishgahroudsari M, Jolfaei AG, Pazouki A. Comparing the excessive daytime sleepiness of obese and non-obese patients. Iran Red Crescent Med J. 2016;18(7):e21964.

10. Hayley AC, Williams LJ, Kennedy GA, Berk M, Brennan SL, Pasco JA. Excessive daytime sleepiness and body composition: a population-based study of adults. PLoS One. 2014;9(11):e112238.

11. Fanfulla F, Grassi M, Marandola P, Taino G, Fulgoni P, Imbrani M. Excessive daytime sleepiness works together with other sleep disorders in determining sleepiness-related events in shift workers. G Ital Med Lav Ergon. 2013;35(3):151-6

12. Kalchiem-Dekel O, Westreich R, Regev A, Novack V, Goldberg M, Maimon N. Snoring intensity and excessive daytime sleepiness in subjects without obstructive sleep apnea. Laryngoscope. 2016;126(7):1696-701.

13. Theorell-Haglöw J, Akerstedt T, Schwarz J, Lindberg E. Predictors for development of excessive daytime sleepiness in women: a populationbased 10-year follow-up. Sleep. 2015;38(12):1995-2003.

14. Svensson M, Franklin KA, Theorell-Haglöw J, Lindberg E. Daytime sleepiness relates to snoring independent of the apnea-hypopnea index in women from the general population. Chest. 2008;134(5):919-24.

15. Klobučníková K, Šiarnik P, Čarnická Z, Kollár B, Turčáni P. Causes of excessive daytime sleepiness in patients with acute stroke - a polysomnographic study. J stroke. Cerebrovascular Dis. 2016;25(1):83-6.

16. Gander PH, Marshall NS, Harris R, Reid P. The Epworth sleepiness scale: influence of age, ethnicity, and socioeconomic deprivation. Epworth sleepiness scores of adults in New Zealand. Sleep. 2005;28(2):249-53.

17. Cai $S$, Chen R, Zhang Y, et al. Correlation of Epworth sleepiness scale with multiple sleep latency test and its diagnostic accuracy in assessing excessive daytime sleepiness in patients with obstructive sleep apnea hypopnea syndrome. Chin Med J. 2013;126(17):3245-50.

18. Ramar K, Guilleminault C. Excessive daytime sleepiness and obstructive sleep apnea syndrome. Sleep Med Clin. 2006;1:63-78.

19. Ulfberg J, Carter N, Talback M, Edling C. Excessive daytime sleepiness at work and subjective work performance in the general population and among heavy snorers and patients with obstructive sleep apnea. Chest. 1996;110(3):659-63.

20. Zwahlen D, Jackowski C, Pfäffli M. Sleepiness, driving, and motor vehicle accidents: a questionnaire-based survey. J Forensic Legal Med. 2016;44:183-7.

21. Ward KL, Hillman DR, James A, et al. Excessive daytime sleepiness increases the risk of motor vehicle crash in obstructive sleep apnea. J Clin Sleep Med. 2013;9(10):1013-21.

22. King N, Pickett W, Hagel L, Lawson J, Trask C, Dosman JA. Impact of excessive daytime sleepiness on the safety and health of farmers in Saskatchewan. Can Respir J. 2014;21(6):363-9.

23. Uehli K, Mehta AJ, Miedinger D, et al. Sleep problems and work injuries: a systematic review and meta-analysis. Sleep Med Rev. 2014;18:61-73.

24. Pahwa $P$, Karunanayake CP, Hagel $L$, et al. Prevalence of high Epworth sleepiness scale scores in a rural population. Can Respir J. 2012;19(2):e10-4

25. Paine SJ, Gander PH, Harris RB, Reid P. Prevalence and consequences of insomnia in New Zealand: disparities between Maori and non-Maori. Aust N Z J Public Health. 2005;29(1):22-8.

26. Sin DD, Wells H, Svenson LW, Man SFP. Asthma and COPD among aboriginals in Alberta. Canada Chest. 2002;121(6):1841-6.

27. Health Canada. A Statistical Profile on the Health of First Nations in Canada: Health Services Utilization in Western Canada, 2000. Health
Canada: Ottawa, ON 2009. http://www.hc-sc.gc.ca/fniah-spnia/alt formats/fnihb-dgspni/pdf/pubs/aborig-autoch/2009-stats-profil-vol2eng.pdf.

28. Canada H. A statistical profile on the health of First Nations in Canada: determinants of health 1999-2003. Report no.: 3555. Ottawa, ON: Health Canada; 2009. Available from: http://www.hc-sc.gc.ca/fniah-spnia/alt_ formats/fnihb-dgspni/pdf/pubs/aborig-autoch/2009-stats-profil-eng.pdf

29. Reading $\mathrm{CL}$, Wien $\mathrm{E}$. Health inequalities and social determinants of aboriginal peoples' health. Prince George, BC, Canada: National Collaborating Centre for Aboriginal Health; 2009. https://www.ccnsa-nccah. ca/docs/determinants/RPT-Healthlnequalities-Reading-Wien-EN.pdf

30. Ellis E, Gallant V, Miron M, Phypers M, Scholten D. Special report of the Canadian Tuberculosis Committee. Tuberculosis among the Aboriginal People of Canada, 2000 to 2004. In tuberculosis in Canada. Public Health Agency of Canada: Ottawa, ON, 2007. Available from: http://publications.gc.ca/collections/collection_2008/phac-aspc/HP37-52004E.pdf.

31. Haché T. Commercial Tobacco in First Nations \& Inuit Communities. Toronto: Non-Smokers' Rights Association/ Smoking and Health Action Foundation, 2009. Available from: https://nsra-adnf.ca/wp-content/uploads/2016/08/ Commercial_Tobacco_in_First_Nations_and_Inuit_Communities.pdf.

32. The National Aboriginal Economic Development Board. The aboriginal economic progress report 2015. 2015. Available from: http:// cfarsociety.ca/wp-content/uploads/2015/04/NAEDB-progress-reportjune-2015.pdf

33. Kelly-Scott K, Smith K. Aboriginal peoples: fact sheet for Canada. Ottawa, ON: Statistics Canada; 2015. Available from: http://www.statcan.gc.ca/pub/ 89-656-x/89-656-x2015001-eng.htm\#a5

34. Indigenous and northern affairs Canada. Indigenous peoples and communities. Terminology. 2012. Available from: https://www.aadnc-aandc. gc.ca/eng/1100100013785/1304467449155.

35. Froese $\mathrm{CL}$, Butt $\mathrm{A}$, Mulgrew A, et al. Depression and sleep-related symptoms in an adult, indigenous, north American population. J Clin Sleep Med. 2008; 4(4):356-61.

36. Government of Saskatchewan. Saskatchewan Aboriginal Peoples. 2011. Available from: http://www.stats.gov.sk.ca/stats/pop/ 2011 Aboriginal\%20People.pdf.

37. Pahwa P, Abonyi S, Karunanayake C, et al. A community-based participatory research methodology to address, redress, and reassess disparities in respiratory health among First Nations. BMC Res Notes. 2015:8:199.

38. Johns MWA. New method for measuring daytime sleepiness: the Epworth sleepiness scale. Sleep. 1991;14(6):540-5.

39. Johns MW. Reliability and factor analysis of the Epworth sleepiness scale. Sleep. 1992;15(4):376-81

40. Johns MW. Daytime sleepiness, snoring, and obstructive sleep apnea. The Epworth sleepiness scale. Chest. 1993;103(1):30-6.

41. Johns MW. Sleepiness in different situations measured by the Epworth sleepiness scale. Sleep. 1994;17(8):703-10.

42. Chaudry A, Wimer C. Poverty is not just an indicator: the relationship between income, poverty, and child well-being. Acad Pediatr. 2016;16(3 Suppl):S23-9.

43. Kovesi T. Respiratory disease in Canadian first nations and Inuit children. Paediatr Child Health. 2012;17(7):376-80.

44. Levy H. Income, poverty, and material hardship among older Americans. RSF. 2015;1(1):55-77.

45. Grandner MA, Patel NP, Gehrman PR, et al. Who gets the best sleep? Ethnic and socioeconomic factors related to sleep complaints. Sleep Med. 2010; 11(5):470-8.

46. Umlauf MG, Bolland AC, Bolland KA, Tomek S, Bolland JM. The effects of age, gender, hopelessness, and exposure to violence on sleep disorder symptoms and daytime sleepiness among adolescents in impoverished neighborhoods. J youth. Adolescence. 2015;44(2):518-42.

47. Grandner MA, Williams NJ, Knutson KL, Roberts D, Jean-Louis G. Sleep disparity, race/ethnicity, and socioeconomic position. Sleep Med. 2016;18:7-18.

48. Leone T, Coast E, Narayanan S, de Graft Aikins A. Diabetes and depression comorbidity and socio-economic status in low and middle income countries (LMICs): a mapping of the evidence. Glob Health. 2012:8:39.

49. Leigh JP, Are DJ. Low wages risk factors for hypertension? Eur J Pub Health. 2012;22(6):854-9.

50. Szanton SL, Seplaki CL, Thorpe RJ, Jr., Allen JK, Fried LP. Socioeconomic status is associated with frailty: the Women's health and aging studies. J Epidemiol Community Health 2010; 64(1):63-67. 
51. Kaneita $Y$, Ohida $T$, Uchiyama $M$, et al. Excessive daytime sleepiness among the Japanese general population. J Epidemiol. 2005;15(1):1-8.

52. Karachaliou F, Kostikas K, Pastaka C, Bagiatis V, Gourgoulianis Kl. Prevalence of sleep-related symptoms in a primary care population - their relation to asthma and COPD. Prim Care Respir J. 2007;16(4):222-8.

53. Koutsourelakis I, Perraki E, Bonakis A, Vagiakis E, Roussos C, Zakynthinos S. Determinants of subjective sleepiness in suspected obstructive sleep apnoea. J Sleep Res. 2008;17(4):437-43.

54. Lee JH, Han DH, Song JW, Chung HS. Diagnostic and therapeutic problems of pulmonary tuberculosis in elderly patients. J Korean Med Sci. 2005;20(5):784-9.

55. Slater G, Pengo MF, Kosky C, Steier J. Obesity as an independent predictor of subjective excessive daytime sleepiness. Respir Med. 2013;107(2):305-9.

56. Fernandez-Mendoza J, Vgontzas AN, Kritikou I, et al. Natural history of excessive daytime sleepiness: role of obesity, weight loss, depression, and sleep propensity. Sleep. 2015;38(3):351-60.

57. Newman $A B$, Spiekerman $C F$, Enright $P$, et al. Daytime sleepiness predicts mortality and cardiovascular disease in older adults. J Am Geriatr Soc. 2000; 48(2):115-23.

58. Shahar E, Whitney CW, Redline S, et al. Sleep-disordered breathing and cardiovascular disease. Cross-sectional results of the sleep heart health study. Am J Respir Crit Care Med. 2001:163(1):19-25.

59. Irwin ED, Reicks P, Beal A, Byrnes M, Matticks C, Beilman GA. Prospective study of the role of sleep related disordered breathing as a risk factor for motor vehicle crashes and the development of systemic complications in non-commercial drivers. World J Emerg Surg. 2014;9:2.

60. Johnson KD, Patel SR, Baur DM, et al. Association of sleep habits with accidents and near misses in United States transportation operators. J Occup Environ Med. 2014 May;56(5):510-5.

61. Janzen B, Karunanayake C, Pahwa P, et al. Exploring diversity in socioeconomic inequalities in health among rural dwelling Canadians. J Rural Health. 2015;31(2):186-98.

62. Kapur VK, Redline S, Nieto FJ, Young T, Newman AB, Henderson JA. The relationship between chronically disrupted sleep and healthcare use. Sleep. 2002:25(3):289-96

63. Leung RST, Comondore VR, Ryan CM, Stevens D. Mechanisms of sleepdisordered breathing: causes and consequences. Pflugers Arch - Eur J Physiol. 2012;463:213-30.

64. Guilleminault C, Lopes MC, Hagen CC, de Rosa A. The cyclic alternating pattern demonstrates increased sleep instability and correlates with fatigue and sleepiness in adults with upper airway resistance syndrome. Sleep. 2007:30(5):641-7.

65. Zanobetti A, Redline S, Schwartz J, et al. Associations of $\mathrm{PM}_{10}$ with sleep and sleep-disordered breathing in adults from seven U.S. urban areas. Am J Respir Crit Care Med. 2010;182(6):819-25.

66. Park JH, Gold DR, Spiegelman DL, Burge HA, Milton DK. House dust endotoxin and wheeze in the first year of life. Am J Respir Crit Care Med. 2001;163(2):322-8

67. Michel O, Kips J, Duchateau J, et al. Severity of asthma is related to endotoxin in house dust. Am J Respir Crit Care Med. 1996;154(6 Pt 1):1641-6.

68. Lin Y, Li Q, Zhang X. Interaction between smoking and obstructive sleep apnea: not just participants. Chin Med J. 2012;125(17):3150-6.

69. Rosales-Mayor E, de Castro JR, Huayanay L, Zagaceta K. Validation and modification of the Epworth sleepiness scale in Peruvian population. Sleep Breath. 2012;16(1):59-69.

\section{Submit your next manuscript to BioMed Central and we will help you at every step:}

- We accept pre-submission inquiries

- Our selector tool helps you to find the most relevant journal

- We provide round the clock customer support

- Convenient online submission

- Thorough peer review

- Inclusion in PubMed and all major indexing services

- Maximum visibility for your research

Submit your manuscript at www.biomedcentral.com/submit
) Biomed Central 